\title{
Antiglycation activity of Ricinus communis
}

\author{
Faheem Ahmed ${ }^{1 *}$ and Mohsin Iqbal ${ }^{2}$ \\ ${ }^{1}$ Biocell Lab, Department of Biochemistry, University of Agriculture, Pakistan \\ ${ }^{2}$ Industrial Biotechnology Lab, Department of Biochemistry, University of Agriculture, Pakistan
}

Submission: February 21, 2018; Published: March 06, 2018

"Corresponding author: Faheem Ahmed and Mohsin Iqbal, Department of Biochemistry, University of Agriculture, Faisalabad, Pakistan, Tel: 03136763676, Email: mohsiniqbal5050@gmail.com

Abstract

Ricinus communis is a plant whose different parts are used for the preparation of herbal medicines. In current research, the root part of Ricinus communis was used to check its ability for antiglycation. The glycation induces diabetes mellitus. The antiglycation is helpful to retard its effect. It could be proved a good practical way to decrease the diabetes mellitus. All the extracts showed antiglycation activity on $3 \mathrm{rd}$, $7^{\text {th }}$ and $11^{\text {th }}$ days but $n$-butanol extract gave maximum ( $88 \%, 50 \%, 47 \%$ inhibition) activity. The roots of Ricinus communis had shown good antiglycation activity and it could be proved as a good source of herbal medicine.

Keywords: Extracts; Antiglycation; Diabetes mellitus; Ricinus communis; Herbal medicines

Abbreviations: T1DM: Type 1 Diabetes Mellitus; T2DM: Type 2 Diabetes Mellitus; GDM: Gestational Diabetes Mellitus; MODY: Maturity Onset Diabetes Mellitus in Young; HLA: Human Leukocyte Antigen; AGEs: Advanced Glycation End Products; BSA: Bovine Serum Albumin

\section{Aims and Background}

Diabetes is one of the chronic disease, chronic diseases show their symptoms after long period of time. It is a disease in which the normal physical processes that control the blood glucose level of a person and maintain blood glucose in normal range do not work properly. The glucose is one of the important factors for the normal functionality of body. It is quickest and cheapest source of energy. Many organs cannot store glucose and they require continuous supply of glucose like brain. The major source of glucose is food and drinks. The hormones like insulin, glucagon and glucocorticoid normally regulate the glucose concentration. The insulin is the main hormone for regulation of glucose. There is chance of diabetes only if body cannot produce required quantity of insulin or body does not have ability to use insulin in proper way or both. The person who is suffering from diabetes cannot convert glucose into glycogen or glucose into energy. So, level of glucose in blood is increased. The diabetes mellitus has two types. These are Type 2 diabetes mellitus (T2DM) and Type 1 diabetes mellitus (T2DM). The diabetes mellitus of Type 1 is mainly autoimmune disease which is caused by $\mathrm{T}$ lymphocytes by autoimmune error and is the main type of diabetes among adults and children. At the time of diagnosis, it is normally difficult to differentiate between the types. In the type 2 diabetes the resistance of body tissues to insulin action and progressive failure of insulin production are the main symptoms. The type 2 diabetes mellitus is mostly seen in people with age of 40 or above 40. It can also have diagnosed in young adults and very rarely children. The most common type of diabetes mellitus is type 2 diabetes mellitus among diabetic patients. It accounts for about 85 percent of all diabetic cases. In initial T2DM treatment combination of properly maintained exercise to maintain the weight or reduce the weight and proper diet according to advice of physician are initial strategies used to manage type 2 diabetes. In most of diabetic patients the medication is required like oral glucose lowering medicines or sometimes immediate treatment of patient with insulin treatment for young people diagnosed with T2DM [1].

Diabetes mellitus is a genetic as well as nutritional disorder and it could be clinically metabolic disorder. It is hyperglycemia which is due to problem in insulin secretion. The diabetes mellitus has two major types. The type 2 diabetes mellitus (T2DM) and type 1 diabetes mellitus (T1DM). There are some other types too like Maturity onset diabetes mellitus in young (MODY) and gestational diabetes mellitus (GDM). The T1DM mainly caused by destruction of beta cells. The islets of Langerhans are present in pancreas has beta cells. When there is complete destruction of beta cells it causes complete deficiency of insulin. The destruction may be due to error in immune system in which failure of autoimmune system occurs and $\mathrm{T}$ lymphocytes destroy the beta cells or there are many cases in which reason for destruction are unknown which is called as 
idiopathic etiology. The type 2 diabetes mellitus (T2DM) can be due to insulin resistance which results in deficiency of insulin due to failure in secondary processes of beta cells which are in pancreas. GDM is a type of diabetes mellitus in which any glucose level is not tolerated when it is first recognized during period of pregnancy [1].

The prevalence of diabetes mellitus disease is quite high in developed countries as compared to developing countries. Diabetes mellitus is more common in women. The T2DM patients are $90 \%$ among all the diabetic patients. The prevalence of diabetes mellitus among the adults was analyzed in whole world. It was analyzed that diabetes mellitus was 4 percent in whole population of world. It was expected that this disease will rise up to $5.4 \%$ till 2025 . The 135 million people were victim of disease in 1995 and it was expected that 300 million people could be victim of disease up till 2025. It was analyzed in 1995 that increase in disease will be more in developing countries as compared to developed countries. In developed countries, it expected increase could be 42 percent which is between fiftyone to seventy-two million. In developing countries, it could be increased from 84 to 228 million. It was expected that till 2025 the 75 diabetic patients will be living in developing countries and it was also estimated that the majority of people with diabetes mellitus will have age between 45 to 64 years. It is analyzed that the diabetic patients in whole world today are 246 million and in developed countries their age is more than 65 . The diabetes mellitus is increasing continuously in urban areas [1].

Diabetes Mellitus is classified as it has two types. First class has disorder of carbohydrate which results in high sugar level in blood and by lesser insulin production (type 1 diabetes mellitus) and second class has insulin resistance (T2DM). This disease very widespread and lots of research has been done to give cost effective and efficient therapeutic remedies and medicines for diabetes [2]. T1DM is considered as a reduction in insulin. There is need of insulin replacement for the survival of patient. The T1DM mostly seen in young adults but it is not necessary that it is disease of young it can occur at any age of life. There is complete insulin deficiency in T1DM. There is error of autoimmune response. $\mathrm{T}$ cell mediated autoimmune response can cause destruction of beta cells of pancreas. The islets of Langerhans have beta cells which is present in pancreas. It is the type of diabetes mellitus which can cause disease in young children but it can present in adults too. There are few symptoms of diabetes mellitus like polydipsia, weight loss and polyuria. The main pathophysiology is the deficiency in insulin secretion which can be the reason for high glucose level in blood which is condition of hyperglycemia with a propensity to develop ketoacidosis. The onset of T1DM mostly results into illness which can result into infection. There are few alleles which can be inherited collectively. These are HLA class 2 alleles which are $D Q A, D Q B$ and $D R B$ alleles. The type 1 diabetes mellitus has association to antigen of leukocytes and also associated too few allotypes of $D Q B, D R B$ and $D Q A$ alleles which are present on $D Q$ genes of second exons of DNA. One or more glutamic acid decarboxylase 65 (GAD65), including islet cell, insulin, autoantibodies, tyrosine phosphatase IA-2b, antibodies and zinc transporter can be seen in 85 to 90 percent people. The destruction rate of beta cell varies normally and occurs very fastly at young ages. The type 2 diabetes mellitus present in adults but few have proper quantity of beta cell function for avoiding from dependency on insulin. There are autoantibodies which are considered as autoimmune diabetes of adults. The ketoacidosis is a problem which can result in the no usage of sugar because of complete deficiency of insulin. Type 1 diabetes mellitus does not have autoimmunity, it is related to ketoacidosis there is the need of insulin treatment. The people with Asian and African ancestry has idiopathic diabetes T1DM type $\mathrm{B}$ which is a type of diabetes mellitus in more common way. It is mainly due to obesity. There are children with obesity and it is due to fast food consumption. The obese children have Type 1 Diabetes Mellitus. Acanthosis nigricans (insulin resistance evidence), glucose, C-peptide levels and fasting insulin are major diagnostic components to analyze the T1DM. Presence of insulin, phosphatase autoantibodies, glutamic acid decarboxylase and islet cell are useful in differentiating the difference between T2DM and T2DM. It is helpful although both types are resistant to insulin and insulin deficiency. These both can be present in the same patients but the type 2 diabetes mellitus can present at higher level having less $\mathrm{C}$ peptide levels and minimum function of islet of Langerhans cell [3].

The T2DM is very spread in diabetic patients and it has characteristic of reduction in the action of insulin or deficiency in insulin secretion. This disease can be initially treated by managing the lifestyle. There is need for modification in lifestyle such as proper diet, weight loss, orally medication which can lower the glucose level and increase in exercise. The type 2 diabetes has been termed as a disease of old age people but in current reports it is shown that it is also diagnosed in younger aged people. So, the young and old have equal chance of T2DM. The non-modifiable and modifiable factors are present there. The modifiable factors are physical inactivity and poor diet. Both of these are cause of obesity and overweight. The overweight is the main modifiable factor for developing T2DM for young people because there are 85 percent of children having T2DM are obese. Obesity in children is mostly due less activity, reduced exercise and fast food. The fast food is major cause of this disease. The rate of type 2 diabetes mellitus is quite high in whole world because of increased rate of obesity. There are high rates of overweight and obese people in the population as a whole. The obesity is common in all ages like children, young people and old people. During the year 2011 to 2012 in whole world there were 25 percent children having age between 5 years to 17 years were overweight or obese. Fast food was considered as major reason behind this. The diabetes can spread genetically so maternal diabetes mellitus which is termed as gestational diabetes mellitus and preexisting T1DM and T2DM. The T2DM also has risk factor of development when child is in womb. The type 2 diabetes mellitus can occur when females are 
reproduction period which is termed as gestational diabetes mellitus. The chance for gestational diabetes mellitus can be about 5 percent of all pregnancies in world a rough estimate given by world health organization in 2010. The chance of gestational diabetes mellitus increases as the number of children increases. The genetic predisposition of diabetes mellitus is nonmodifiable risk factors. It is shown by pedigree of man families. They are insulin resistance as a result of puberty and ethnicity. Type 2 diabetes mellitus is reaching to higher levels in whole world and there is need to control it by awareness strategies and developing new health care strategies [4].

There are many traditional medicines which are used in whole world for T2DM since ancient times. Many medicinal plant in whole world are practiced by many tribes and ethnic groups for treatment of type 2 diabetes mellitus. There are many treatments available in allopathic system of medicine. The prevalence of T2DM is going to increase in whole world. The main requirement of controlling glucose level in blood in T2DM. The management of blood glucose level is highly required in this disease. There are many herbal medicines are used in whole world to treat the T2DM. Herbal medicines are quite good because of their safety and better efficacy as compared to synthetic drugs. Many medicinal plants are studied in whole world for their effect against diabetes mellitus. There are many agents which are hypoglycemic in their nature are found in plants. These agents are safe and effective for treatment of hyperglycemia. Many species of plants having origin from different families are quite effective in treatment of type 2 diabetes mellitus [5].

Table 1: Antiglycation activity.

\section{Experimental}

\section{a . Antiglycation Activity}

The advanced glycation end-products (AGEs) formation was assessed by characteristic fluorescence reported by Matsuda et al. [6]. Briefly, the reaction mixture of $100 \mathrm{mg}$ D-glucose + $10 \mathrm{mg}$ bovine serum albumin (BSA) in $1 \mathrm{~mL}$ sodium phosphate buffer (pH 7.2) was incubated at $60 \mathrm{oC}$ for 2 days with or without the test compound. The reaction solution $(0.2 \mathrm{~mL})$ was diluted with water $(2 \mathrm{~mL})$, and the intensity of fluorescence was measured using a fluorophotometer (Luminescence Spectrometer LS50B, Perkin-Elmer Ltd, Buckinghamshire, England) at an excitation wavelength of $370 \mathrm{~nm}$ and an emission wavelength of $440 \mathrm{~nm}$. The reaction mixture without D-glucose was used as a blank solution. Measurements were performed in duplicate and aminoguanidine was used as a reference compound.

\section{Calculation of $50 \%$ Inhibitory Concentration (IC50\%):}

$$
\% \text { Inhibition }=100-[(O D(\text { test }) / O D(\text { control }) X 100]
$$

OD test= Experimental value; OD blank= Value of control

\section{Results and Discussion}

The glycation occurred when glucose or fructose form bond with lipid and protein to form advanced glycation end products (AGEs). The protein and reducing sugars are condensed and it causes glycation to produce ketoamins [7]. The antiglycation potential activity of roots of Ricinus communis was assessed with the help of authorized methodology. The readings were taken on $3^{\text {rd }}, 7^{\text {th }}$ and $11^{\text {th }}$ day (Table 1 ).

\begin{tabular}{|c|c|c|}
\hline Sr. No. & Fractions & Mean \pm SE \\
\hline 1 & Methanol & $0.600 \pm 0.095 \mathrm{AB}$ \\
\hline 2 & Ethyl acetate & $0.364 \pm 0.160 \mathrm{~B}$ \\
\hline 3 & n-hexane & $0.468 \pm 0.030 \mathrm{~B}$ \\
\hline 4 & Chloroform & $0.559 \pm 0.043 \mathrm{AB}$ \\
\hline 5 & Ethanol & $0.611 \pm 0.033 \mathrm{C}$ \\
\hline 6 & $n$-butanol & $0.324 \pm 0.108 \mathrm{~B}$ \\
\hline 7 & Aqueous & $0.697 \pm 0.095 \mathrm{AB}$ \\
\hline 8 & Positive Control & $0.647 \pm 0.029 \mathrm{AB}$ \\
\hline 10 & PABA & $0.957 \pm 0.014 \mathrm{~A}$ \\
\hline 11 & Niacin & $0.758 \pm 0.018 \mathrm{AB}$ \\
\hline
\end{tabular}

Data represented as \pm standard error.

Table 2: Antiglycation activity.

\begin{tabular}{|c|c|c|}
\hline & Comparison of Means & Mean \pm SE \\
\hline Sr. No. & Days & $0.555 \pm 0.087 \mathrm{~A}$ \\
\hline 1 & $3^{\text {rd }}$ day & $0.624 \pm 0.048 \mathrm{~B}$ \\
\hline 3 & $7^{\text {th }}$ day & $0.627 \pm 0.059 \mathrm{AB}$ \\
\hline
\end{tabular}


Table 3: ANOVA for antiglycation activity.

\begin{tabular}{|l|l|l|l|l|l|}
\hline Sr. No. & Source of variance & Degrees of freedom & Sum of squares & Mean squares & F-value \\
\hline 1 & Days & 03 & 0.03627 & 0.01813 & 0.74 NS \\
\hline 2 & Treatment & 10 & 0.98848 & 0.09885 & $4.04^{* *}$ \\
\hline 4 & Error & 20 & 0.48941 & 0.02447 & \\
\hline
\end{tabular}

NS = Non-significant $(P>0.05) ;{ }^{* *}=$ Highly significant $(P<0.01)$.

Table 4: Percentage antiglycation activity.

\begin{tabular}{|c|c|c|c|}
\hline \multicolumn{3}{|c|}{ Time } & $\mathbf{1}^{\text {th }}$ Day \\
\hline Fractions & $\mathbf{3}^{\text {rd }}$ Day & 34 & 45 \\
\hline Methanol & 15 & 33 & 43 \\
\hline Ethanol & 71 & 35 & 44 \\
\hline Aqueous & 67 & 48 & 37 \\
\hline Chloroform & 52 & 21 & 52 \\
\hline Ethyl Acetate & 87 & 50 & 47 \\
\hline$n$-butanol & 88 & 33 & 20 \\
\hline n-hexane & 03 & 42 & 47 \\
\hline Niacine & 53 & 50 & 32 \\
\hline Metformine & 15 & 18 & 19 \\
\hline
\end{tabular}

Data represented as percentage.

Means sharing similar letters are statistically non-significant $(\mathrm{P}>0.05)$. The metformin, PABA, positive control, ethanol and $n$-hexane are sharing similar letters. They non-significant with respect to each other. Chloroform and aqueous are sharing similar letters so they are non-significant to each other. The Niacin, aqueous, $n$-butanol and chloroform are significant as compared to positive control (Table 2). Means sharing similar letters are statistically non-significant $(\mathrm{P}>0.05)$. All the values are significant with respect to each other. They are not sharing similar alphabets (Tables 3 \& 4) (Figure 1).

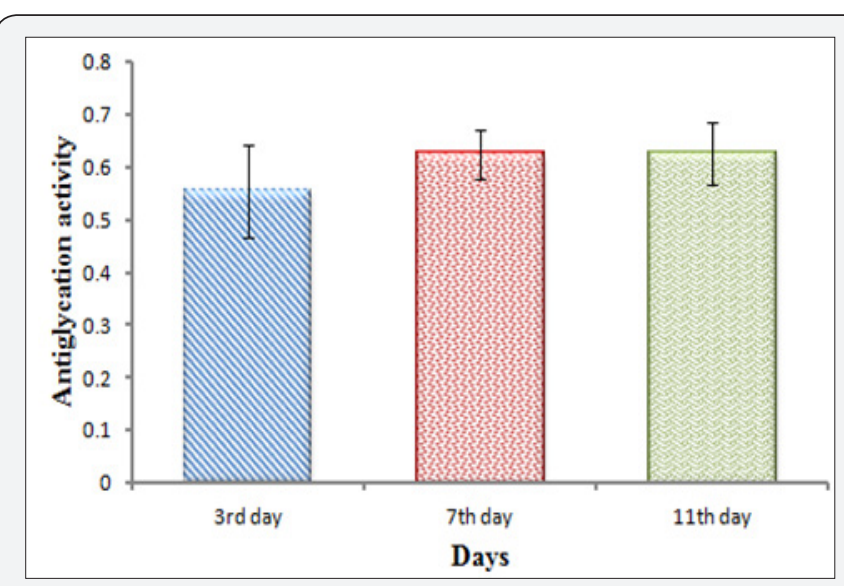

Figure 1: Comparison of antiglycation activity on different days.

The Aloe vera extracts were analyzed for antiglycation activity. The methanol and ethanol extracts were taken. They were analyzed and they had shown activity of $33 \%$ and $54 \%$ [8]. The benzene, petroleum ether and methanol extracts were analyzed for antiglycation activity. They showed $11 \%$ to $60.3 \%$ activity [9]. In my analysis the seven extracts had shown good inhibition in antiglycation activity. The $n$-hexane had the least activity of $3 \%$ in the analysis after $3^{\text {rd }}$ day. The analysis was done after $3^{\text {rd }}, 7^{\text {th }}$ and $11^{\text {th }}$ days. After $3^{\text {rd }}$ day $n$-butanol, ethyl acetate, aqueous and chloroform extracts gave $88 \%, 87 \%, 67 \%$ and $52 \%$ inhibitory activity. After $7^{\text {th }}$ day $n$-butanol and chloroform gave $50 \%$ and $48 \%$ inhibitory activity. After $11^{\text {th }}$ day ethyl acetate and $n$-butanol gave $52 \%$ and $47 \%$ inhibition activity. These all extracts could be used for herbal medicinal values.

\section{Outcomes}

Ricinus communis showed good antiglycation activity. This activity is quite good for its usage against the diabetes mellitus disease. Seven extracts were prepared by roots. These were aqueous, ethanol, methanol, $n$-hexane, $n$-butanol, chloroform and ethyl acetate. All the extracts showed antiglycation activity on $3^{\text {rd }}, 7^{\text {th }}$ and $11^{\text {th }}$ days but $n$-butanol extract gave maximum $(88 \%$, $50 \%, 47 \%$ inhibition) activity. So, the Ricinus communis could be used as herbal medicines to reduce diabetes mellitus. Ricinus communis has good potential against glycation to decrease diabetes mellitus.

\section{References}

1. Negrato C, Antonio M, Junior R, Megalhaes V, Kostrich L, et al. (2013) Insuline analogues in the treatment of diabetes in pregnancy. Versila biblioteca dig 13: 137-141. 
2. Rae K, AD Lee, NL Llanos (2013) The effect of Momordica charantia crude leaf extraction on the enzyme kinetics of porcine alpha amylase. Res Cong J De La Salle Uni Manila 34: 141-146.

3. Sarah W, MB Bchir, G Roglic, MDA Green, R Sicree, et al. (2014) Global prevalence of diabetes. J Epid Health Serv Psycho Res 27(5): 10471053.

4. Menker A, S Casagrande, L Geiss, CC Cowie (2015) Prevalance and trends in diabetes mellitus among adults in the United States, 19882012. JAMA 314(10): 1021-1029.

5. Akram M (2013) Diabetes mellitus type 2 a review of treatment, strategies and options. J Diabetes Metlab 4: 4-9.

6. Matsuda H, T Wang, H Managi, M Yoshikawa (2003) Structural requirements of flavonoids for inhibition of protein glycation and radical scavenging activities. Bio Org Med Chem 11(24): 5317-5323.

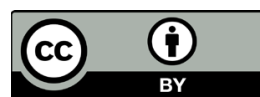

7. Kazeem MI, MA Akanji, RM Hafizur, MI Chaudhary (2012) Antiglycation, antioxidant and toxicological potential of polyphenol extracts of alligator pepper, ginger and nutmeg from Nigeria. Asian Pac J Trop Biomed 2(9): 727-732.

8. Shudha P, SS Zinjarde, SY Bhargava, AR Kumar (2011) Potent $\alpha$-amylase inhibitory activity of Indian Ayurvedic medicinal plants. BMC Complement Altern Med 11: 5.

9. Maurakami T, A Emoto, H Matsuda, M Yoshikawa (2001) Medicinal food stuffs. Part XXI. Structures of new cucuritane type triterpene glycosides, goyaglycosides -a,-b,-c,-d,-e,-f,-g, and -h and new oleananetype triterpene saponins, goyasaponins I, II and III. From the fresh fruit of Japanese Momordica charantia L. Chem Pharma Bull 49: 54-63.

Your next submission with Juniper Publishers
will reach you the below assets
- Quality Editorial service
- Swift Peer Review
- Reprints availability
- E-prints Service
- Manuscript Podcast for convenient understanding
- Global attainment for your research
- Manuscript accessibility in different formats
( Pdf, E-pub, Full Text, Audio)
- Unceasing customer service
Track the below URL for one-step submission
https://juniperpublishers.com/online-submission.php

